\title{
PRÁTICAS SEGREGACIONISTAS EM PEQUENOS TERRITÓRIOS: O CASO DE IEPÊ- SP
}

Mateus Marques Monteiro, Victor Martins de Aguiar

Universidade do Oeste Paulista - UNOESTE, Curso de Arquitetura e Urbanismo, Presidente Prudente, SP. Email: mateusmm 96@hotmail.com

\section{RESUMO}

O trabalho articula considerações teóricas acerca das práticas e processos de segregação socioespacial, assim como seus impactos no espaço intraurbano, com enfoque para "pequenos territórios". Os estudos, em nível de seu recorte analítico, foram direcionados à pequena cidade integrante da microrregião de Presidente Prudente, denominada lepê. A partir desse panorama, este estudo objetiva a discussão acerca dos processos segregadores resultantes na cidade, suas plataformas de atuação e principais impactos. Os procedimentos metodológicos adotados consistiram na revisão bibliográfica e em análises exploratórias e inerentes ao âmbito socioespacial de lepê. De maneira geral, as visitas de campo realizadas, assim como a vivência citadina, acabaram indicando que tais práticas segregacionistas na cidade encontram diversos campos de origem, como a partir da localização dos conjuntos habitacionais de interesse social, e, a certa maneira, são impulsionadas pelo elemento físico natural existente na malha urbana, o córrego Ribeirão dos Patos.

Palavras-chave: segregação socioespacial; pequenos territórios; vulnerabilidade social; conjunto habitacional, lepê.

\section{SEGREGATING PRACTICES IN SMALL TERRITORIES: THE CASE OF IEPÊ-SP}

\begin{abstract}
The present paper articulates theoretical considerations about the practices and processes of socio-spatial segregation, as well as its impacts on the intra-urban space, with a focus on the "small territories". The studies, at the level of its analytical level, were directed to the small city that is part of the microregion of Presidente Prudente, namely lepê. From this point of view, the study aims to discuss the segregation processes in the city, its platforms and its main impacts. The methodological processes involved are bibliographic review, exploratory analysis and inherent to the socio-spatial sphere of the city of lepê. The on-site visits, as well as the city experience, indicate that the segregating practices of the city find several origin fields and, to a certain extent, are driven by the natural physical element located in the urban network, the Ribeirão dos Patos water stream.
\end{abstract}

Keywords: Socio-spatial segregation; Small territories; Social vulnerability; Housing estate; lepê. 


\section{INTRODUÇÃO}

Em um campo mais amplo, o estudo das pequenas cidades não configura uma pauta latente, o que torna seu entendimento dificultoso. Conforme elucidações de Roma (2008), os pequenos territórios - cidades de pequeno e médio porte - acabam sofrendo até mesmo um esforço de conceituação, onde as definições ficam estritas ao campo qualitativo, salientado pela autora nas seguintes estimativas:

O número total de municípios no Brasil é de 5.564, com uma população aproximada de 183.987.291 habitantes. Desses municípios, 5.009 têm um contingente populacional de até cinquenta mil habitantes, o que representa $90,02 \%$ do total de municípios e $34,55 \%$ da população do país (ROMA, 2008, p. 13).

Em suma, os pequenos territórios compreendem uma significativa porção dos municípios brasileiros, assim como uma considerável porcentagem de sua população, onde é lógico pensar que os processos e práticas inerentes à segregação socioespacial não deixem de encontrar seus indicadores no espaço intraurbano e quiçá interurbano, uma vez que tais cidades estabelecem relações de interdependência com centros regionais de maior projeção.

Sobre tais indicadores, Roma (2008), complementa que a segregação socioespacial não atua apenas na dimensão objetiva, observada através da separação de segmentos sociais distintos pelo traçado urbano, mas atua também na dimensão subjetiva, que segundo a autora:

[...] permitem entender como as pessoas se sentem em relação aos espaços da cidade e como percebem os diferentes espaços. Podem existir, por exemplo, pessoas que se sentem afastadas, isoladas ou marginalizadas por residirem em determinados espaços, mesmo que não se autodenominem como segregadas. Para apreender a dimensão subjetiva do processo de segregação socioespacial é preciso, também, analisar como os moradores de outros espaços da cidade percebem os referidos espaços segregados (ROMA, 2008, p. 34).

Ou seja, a segregação socioespacial, assim como etimologicamente já determina, estabelece tal dinâmica entre espaço $X$ sociedade, onde o sentido espacial do termo perpassa a condição de reflexo de tais práticas, mas atua também como um elemento determinador dos processos e dinâmicas norteadoras da sociedade em si imbricada (SPOSITO, 2005).

Sendo assim, o presente artigo permeia o estudo das pequenas cidades e dos processos de segregação socioespacial, trazendo como objeto de estudo a cidade de lepêSP, um dos 645 municípios integrantes do Estado de São Paulo ${ }^{1}$ e que com pouco mais de 7.600 habitantes (IBGE, 2010), demonstra algumas práticas segregacionistas, em especial, nos conjuntos habitacionais de interesse social ${ }^{2}$.

\section{METODOLOGIA}

O trabalho desenvolveu-se por intermédio de revisão bibliográfica, com o intuito de compor o embasamento teórico do presente artigo. Aliado a revisão, visitas in loco e análises inerentes ao âmbito socioespacial de lepê auxiliaram o entendimento dos processos de

\footnotetext{
${ }^{1}$ Informação obtida através do Portal do Governo do Estado de São Paulo. Disponível em: <http://www.saopaulo.sp.gov.br/conhecasp/>. Acesso em 01 agosto 2018.

${ }^{2}$ A produção habitacional de interesse social de lepê (1992 - 2018) compreende 8 conjuntos habitacionais amparados por três diferentes órgãos e programas, a saber: Companhia do Desenvolvimento Habitacional Urbano (CDHU), Habitar Brasil e Minha Casa Minha Vida (MCMV). Ao todo, resultando em 557 unidades habitacionais na cidade.
} 
segregação atuantes, assim como subsidiaram uma melhor compreensão do espaço urbano estudado.

\section{DISCUSSÃO}

A região do Pontal do Paranapanema, onde se encontra lepê, começou a ser fortemente ocupada no final do século XIX em decorrência da construção da Estrada de Ferro Sorocabana (LEITE, 1999). Ao campo atual, 2018, o crescimento da cidade encontra-se em processo lento, devido à grande demanda emigratória. Um dos motivos a qual isso se atribui é o isolamento que a cidade sofreu em 1978, onde após a construção da Usina Hidrelétrica de Capivara, os níveis de água dos afluentes do Paranapanema foram elevados, consequentemente alagando a principal via de acesso, a extensão da Rodovia Brigadeiro Eduardo Gomes, que ligava lepê ao Estado do Paraná, do qual faz divisa.

Dessa maneira, a cidade que, segundo relatos informais dos moradores, já teve mais de 30 mil habitantes, atualmente possui, de acordo com o Censo de 2010 do IBGE (Instituto Brasileiro de Geografia e Estatística) apenas 7,628 habitantes. Embora a subordinação a centros regionais seja característica das pequenas territorialidades (GATTI; ZANDONADE, 2017), em decorrência de seu isolamento, lepê tornou-se estritamente dependente de cidades vizinhas, como Rancharia e Presidente Prudente para determinadas atividades, 0 que intensificou seus processos migratórios.

O principal agente motor econômico de lepê compreende a atividade agroindustrial em decorrência da grande quantidade de terras agricultáveis da região. Porém, tal atividade costuma ter concentração de renda em mãos latifundiárias, já que estimativas do IBGE de 2015 demonstram que o PIB (Produto Interno Bruto) da cidade é de R\$200.969.000, sendo o PIB per capita de R\$25.008,55 por habitante ${ }^{3}$. Outras estimativas acerca de trabalho e rendimento, também de 2015 , informam que apenas $17 \%$ da população é formalizada dentro dos postos de serviço, totalizando apenas 1.367 pessoas com carteira assinada. 0 salário médio mensal dos trabalhadores formais é de 2,4 salários mínimos, ou seja, $\mathrm{R} \$$ $1.892,20^{4}$ e o percentual da população com rendimento nominal mensal per capita de até meio salário mínimo é de $33,6 \%$. Em consonância, tais aspectos relativos ao panorama socioeconômico acabam indicando que lepê possui uma distribuição de renda desigual.

Segundo Gatti e Zandonade (2017), os pequenos territórios, na figura das cidades pequenas, possuem certas características atribuídas à dicotomia rural $X$ urbano ${ }^{5}$ comum nas regiões interioranas. Essas características compreendem certas particularidades ligadas ao seu território, a saber: forte presença de elementos naturais, subordinação aos centros regionais, migração permanente ou pendular, relações de proximidade social e persistência em tempos e modos de vida tradicionais. A partir desses aspectos atribuídos à sua dicotomia, prevalecem diferentes modos de socialização, habitação e deslocamento. Porém, assim como em qualquer cidade, os pequenos territórios também são marcados por fraquezas que corroboram para a negligência da dimensão humana.

As cidades pequenas geralmente carregam uma herança ibérica, na figura dos adros, onde a praça é formada em torno da igreja matriz, dessa maneira as áreas mais periféricas sucumbem à falta de espaços de lazer. Um investimento nos espaços públicos nessas regiões

\footnotetext{
${ }^{3}$ O PIB per capita fica abaixo da média nacional de 2015, que é de R\$ 29.321,71 por habitante. No ranking estadual de municípios pelo PIB, lepê ocupa a 235\% posição entre os 645 municípios do Estado de São Paulo (IBGE, 2015).

${ }^{4}$ Levando em conta o salário mínimo vigente em 2015 de R\$ 788,00.

${ }^{5}$ Para Gatti e Zandonade (2017, p. 26), a dicotomia rural $X$ urbano é consequência da localidade rural, diferente de uma localidade prioritariamente agrária, ou seja, de cidades que possuem menos de 50 mil habitantes e com densidade populacional inferior a 80 $\mathrm{hab} / \mathrm{km}^{2}$. Como já discorrido, de acordo com o Censo de 2010, lepê possui 7,628 habitantes que Ihe conferem uma densidade demográfica de $12,81 \mathrm{hab} / \mathrm{km}^{2}$.
} 
pode fomentar uma redistribuição mais democrática da cidade, equipando-as igualitariamente e reduzindo os deslocamentos da população que não encontra lazer nas proximidades, como Gatti e Zandonade (2017, p. 43) elucidam:

Nem sempre o problema está na existência ou não de espaços públicos em regiões distintas da cidade, mas na manutenção e investimentos que estes espaços recebem, que faz com que eles sejam ou não apropriados pela população como espaço de lazer e permanência.

Num âmbito geral, essa característica desigual pela distributiva dos espaços públicos e equipamentos urbanos é melhor percebida quando compreendido os preceitos de segregação socioespacial ao elemento físico que salienta o caráter bipartido de lepê. A esse fenômeno de bipartição do espaço urbano, atribui-se o nome Dual City, no qual Wacquant (2004) estima que tenha surgido em 1968, pela Comissão Kerner ${ }^{6}$, que publicou uma manchete ao título: "our nation is moving towards two societies, one black, one white separate and unequal" [nossa nação está se movendo em direção a duas sociedade, uma negra e outra branca - separadas e desiguais] $]^{7}$.

Marcuse (1989) diz que o conceito de Dual City foi popularizado há pouco, mas basicamente expressa o fenômeno de polarização da cidade, seja na esfera social ou racial, onde esse é ocasionado ou impulsionado por elementos físicos que atuam como propulsores da segregação na cidade. Tal como ocorre em lepê, dado que o pequeno córrego, denominado "Ribeirão dos Patos", age como um desses elementos divisores da organização socioespacial da cidade.

Já Caldeira (2000), em seu livro intitulado "Cidade de Muros: crime, segregação e cidadania em São Paulo", pauta de maneira ordenada as problemáticas da sociedade contemporânea em relação à segregação socioespacial e como a população têm se fechado cada vez mais atrás de muros, intensificando esses processos e corroborando para a justificativa de preconceitos e à naturalização da discriminação social. Também são notáveis alguns desses efeitos em lepê, embora os estudos de Caldeira tenham uma projeção maior por serem realizados na região metropolitana de São Paulo.

Sobre essa discriminação social e seus impactos, atribuídos pela autora à fala do crime $^{8}$, Caldeira (2000, p. 27) ainda complementa:

O medo e a fala do crime não apenas produzem certos tipos de interpretações e explicações, habitualmente simplistas e estereotipadas, como também organizam a paisagem urbana e o espaço público, moldando o cenário para as interações sociais que adquirem novo sentido numa cidade que vai progressivamente se cercando de muros.

Ou seja, a fala do crime ordena o pensamento contemporâneo e dita os preceitos de segregação por todo o corpo da cidade. Apesar de lepê não ter delitos com o viés do crime violento, como ocorre na capital paulista, é notável como os bairros de população mais pobre ou os conjuntos habitacionais de interesse social acabaram sendo implantados na cidade ${ }^{9}$.

\footnotetext{
${ }^{6}$ A comissão Kerner foi uma força-tarefa suprapartidária indicada pelo então Presidente dos Estados Unidos da época, Lyndom Baines Johnson, para investigar e propor medidas à eclosão dos grandes índices de violência norte-americana da época (WACQUANT, 2004).

${ }^{7}$ Tradução livre.

${ }^{8}$ Para Caldeira (2000), a fala do crime compreende qualquer narrativa que contenha o crime como tema central, estas que por ora atuam pejorativamente, intensificam os impactos da segregação socioespacial.

${ }^{9}$ O viés econômico da população mencionada usualmente se relaciona com as práticas socioespaciais por intermédio da localização periférica, ocasionando uma espécie de concentração de famílias com renda similar em localidades próximas ou específicas, assim como uma discrepância em relação ao padrão construtivo das mesmas.
} 
Esse modo análogo à fala do crime existente em lepê, que é mais latente à localização espacial, condiciona seus moradores a fazer o uso de elementos que os cercam e privam da cidade e dos espaços públicos que os circundam. Como uma maneira de agir e pensar, até mesmo os moradores dos conjuntos habitacionais de interesse social da cidade contribuem com a manutenção dessa segregação, edificando muros, portões, cercas e afins. Esses elementos de "proteção", que não compõe a edificação quando a mesma é entregue, vão promovendo a distinção social entre os mesmos.

A edificação e manutenção desses elementos de certa maneira, modificam a experiência urbana, como Caldeira (2000, p. 301) indaga:

Como poderia a experiência de andar nas ruas não ser transformada se o cenário é formado por altas grades, [...] no lugar de jardins, vizinhos conversando, e a possibilidade de espiar cenas familiares através das janelas? A ideia de sair para um passeio a pé, de passar naturalmente por estranhos, o ato de passear em meio a uma multidão de pessoas anônimas, que simboliza a experiência moderna da cidade, estão todos comprometidos numa cidade de muros.

Isto é, o cercamento das cidades impede as mesmas de valer-se de seu caráter de "bem comum", porém pode não ser o único motivo. lepê não possui políticas públicas atuantes com o endosso arquitetônico e urbanístico a fim de mitigar tais processos de distinção social, já que inexiste um Plano Diretor local. Tal contexto resulta em certo desfalque de legislação e também somado a ausência das demais diretrizes urbanas importantes para o crescimento da cidade, como Lei de Uso e Ocupação do Solo e Código de Obras, abre brechas para a autoconstrução e loteamentos ilegais.

\section{RESULTADOS}

Em síntese, algumas dessas questões em lepê são percebidas por suas respectivas posições na malha urbana, onde fica visível a atuação do córrego Ribeirão dos Patos como uma barreira física que isola os bairros mais estigmatizados da cidade. A localização dos conjuntos habitacionais de interesse social denota uma implantação periférica dos mesmos e, a certo ponto, uma concentração próxima ao córrego. A distribuição desigual dos equipamentos urbanos e comunitários, por ora, pode ser categorizada como uma consequência desses mesmos processos segregacionistas, uma vez que se concentram em maior parte na região central e próxima às vias de maior concentração de comércio e serviços (Figura 1). 
Figura 1. Síntese dos processos de segregação socioespacial de lepê.

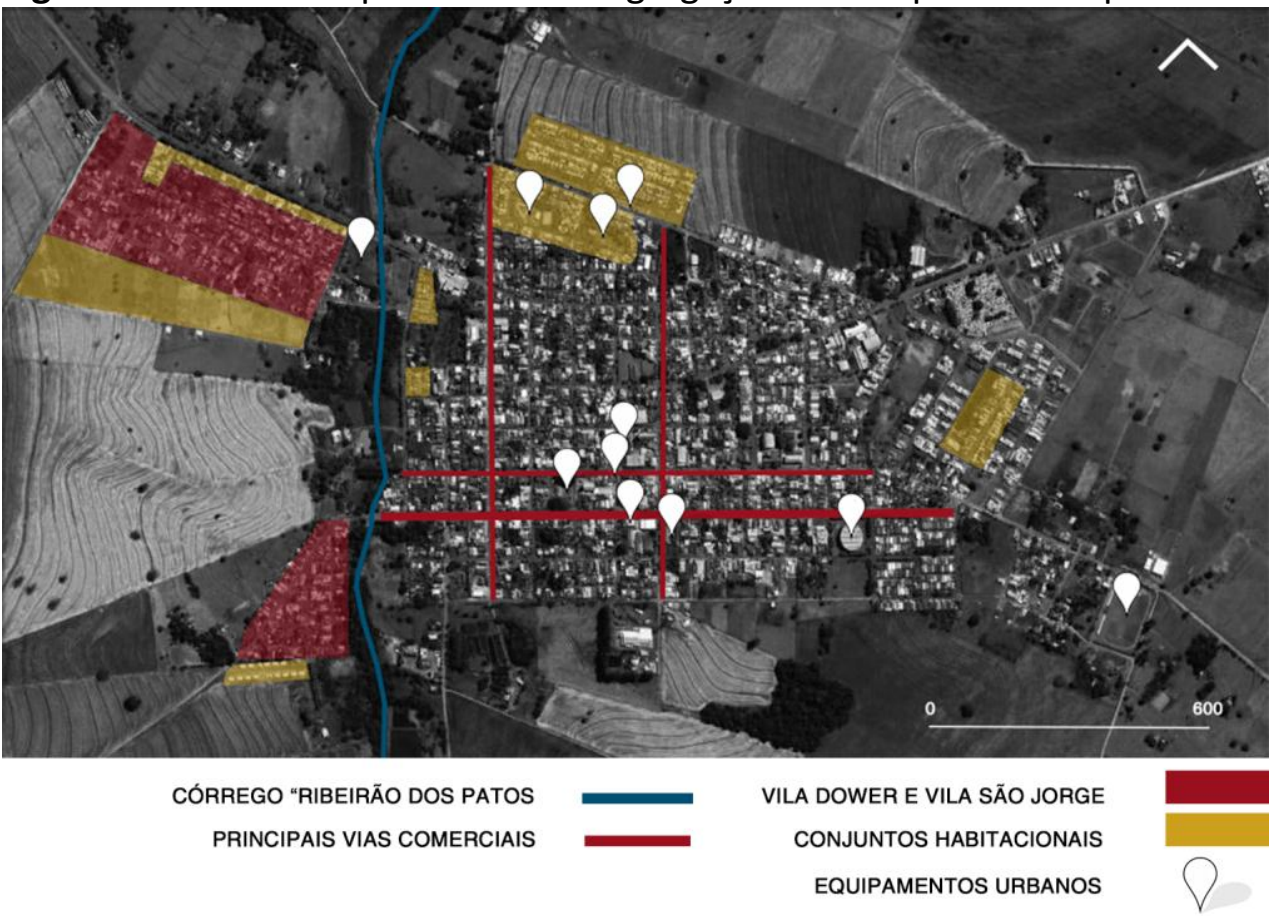

Fonte: Google Earth, 2018. Editado pelos autores, 2018.

Embora algumas das áreas destacadas tenham equipamentos urbanos, os mesmos são caracterizados por certa insuficiência em seu local de inserção, seja pela caracterização de uso restrita à determinada faixa etária ou até mesmo pela rendição à ociosidade, por ora calcada nas práticas segregacionistas já citadas.

\section{CONCLUSÃO}

Tal como discutido nos precedentes do seguinte trabalho, os indicadores de segregação socioespacial encontram duas categorias de atuação, estritos ao campo objetivo e subjetivo. Dessa maneira, pode-se dizer que as práticas objetivas encontram campo quando relacionadas à estruturação urbana de lepê: um primeiro ponto se revela visível a partir da distribuição desigual dos equipamentos urbanos e comunitários e, por conseguinte, a questão dos bairros expostos a um maior índice de vulnerabilidade social - Vila Dower, Vila São Jorge e demais conjuntos habitacionais de interesse social - terem uma localização periférica ${ }^{10}$. Em vista disso, também se ressalta a presença do córrego Ribeirão dos Patos, que pela sua característica física reforça o isolamento das Vilas Dower e São Jorge.

Ao campo subjetivo, fica o exemplo da edificação e manutenção dos elementos físicos segregadores pelos moradores dos conjuntos habitacionais de interesse social. Embora a prática da edificação de muros e colocação de portões e gradis, esteja engendrada no senso comum como parte do estabelecimento de uma falsa sensação de segurança, a construção desses elementos pela população residente dos conjuntos pode, de certa forma, indicar uma espécie de negação ao espaço urbano que lhes foi dado, tangendo assim outra

\footnotetext{
${ }^{10}$ Informações obtidas através dos dados demográficos de distribuição da população segundo grupos do IPVS (Índice Paulista de Vulnerabilidade Social), coordenado pela Assembleia Legislativa do Estado de São Paulo (2010). Os bairros citados - Vila Dower, Vila São Jorge e conjuntos habitacionais de interesse social - são distribuídos entres os Grupos 4 e 5 , indicando vulnerabilidade média (rendimento médio do domicílio de $\mathrm{R} \$ 1.627,00$ ) e vulnerabilidade alta dentro dos setores censitários urbanos (rendimento médio dos domicílios de R4 $1.401,00)$, respectivamente. Em detrimento, as regiões mais centrais são caracterizadas pelo Grupo 2, indicando vulnerabilidade muito baixa (rendimento médio dos domicílios de $\mathrm{R} \$ 2.964,00$ ).
} 
problemática associada à implantação de políticas públicas de habitação: o isolamento da malha urbana.

Vale ressaltar que a presença do elemento físico natural, na figura do córrego Ribeirão dos Patos, não implica unicamente a prática de segregação, mas age como um elemento propulsor da mesma, uma vez que as regiões de fundo de vale são historicamente desvalorizadas por sua associação à insalubridade e por suas possibilidades de alagamento, logo atua como um elemento de separação socioespacial e consequentemente é visto pelos moradores de lepê como uma barreira física deste pequeno território.

\section{REFERÊNCIAS}

CALDEIRA, T. P. R. Cidade de muros: segregação e cidadania em São Paulo. São Paulo: Edusp, 2000.

GATTI, S.; ZANDONADE, P. Espaços públicos: leitura urbana e metodologia de projeto [dos pequenos territórios às cidades médias]. São Paulo: ABCP, 2017.

LEITE, J. F. Alta Sorocabana e o espaço polarizado de Presidente Prudente. Presidente Prudente: Faculdade de Filosofia, Ciências e Letras de Presidente Prudente, 1972.

MARCUSE, P. 'Dual City': a muddy metaphor for a quartered city. International journal of urban and regional research, Erkner, v. 13, n. 4, p. 697-708, 1989. Disponível em: <https://doi.org/10.1111/j.1468-2427.1989.tb00142.x>. Acesso em: 22 mai. 2018.

ROMA, C. M. Segregação socioespacial em cidades pequenas. 2008. 156 f. Dissertação (Mestrado em Geografia) - Faculdade de Ciência e Tecnologia, Universidade Estadual Paulista "Júlio de Mesquita Filho", Presidente Prudente.

SPOSITO, M. E. B. "A produção do espaço urbano" em dez anos de GASPERR: reflexão individual sobre uma trajetória coletiva. In: SPOSITO, E. S. Produção do espaço e redefinições regionais: a construção de uma temática. Presidente Prudente: FCT UNESP/GASPERR, 2005. p. 85-115.

WACQUANT, L. Que é gueto? Construindo um conceito sociológico. Revista de Sociologia e Política, Curitiba, n. 23, p. 155-164, 2004. Disponível em: <http://www.scielo.br/pdf/rsocp/n23/24629.pdf>. Acesso em: 22 mai. 2018. 